Journal of Al Azhar University Engineering Sector

Vol. 11, No. 40, July, 2016, 1067- 1083

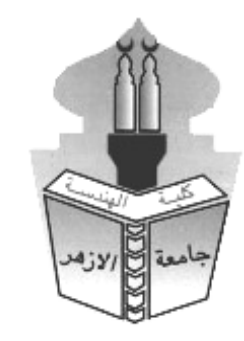

\title{
ASSESMENT OF THE POWER SYSTEM STABILITY WITH LARGE PENETRATION OF WIND TURBINES
}

\author{
A. Tarek, A. Yakout and S. F.Mkhamer \\ Ain Shams University, Cairo, Egypt
}

\begin{abstract}
To overcome adverse impacts caused by conventional synchronous generators (CSGs), renewable energies is replacing the conventional synchronous generators; especially wind turbine generators (WTGs) technology. This paper studies the stability of power system with large wind farms. simulation results show the power system stability with large wind farms are further reliable and stable than CSG .further more Doubly Fed Induction Generator ( DFIG )has more positive damping effect than Fixed Speed Induction Generator( FSIG)

KEYWORDS: Conventional Synchronous Generators (CSGs), Wind Turbine Generators (WTGs), Fixed Speed Induction Generator (FSIG), Doubly Fed Induction Generators (DFIG), Power System Stabilizer (PSS), power system stability, MATLAB/ SIMULINK.
\end{abstract}

\section{INTRODUCTION}

Wind power generation has experienced an enormous growth in the last years and has been recognized as an environmentally friendly and economically continuous means of electric power generation. Shortly, wind power penetration in electrical power systems will increase and will start to replace the output of conventional synchronous generators (CSGs). As a result, wind farms will affect the overall power system behavior. Hence, the impact of wind energy on the dynamics of power systems should be studied thoroughly to recognize potential problems and to develop actions to alleviate those problems.

(WTGs) affect the dynamic behavior of the power system in a way that might be different from CSGs $[1,2]$. The best Location of WTGs to optimize electromechanical oscillations in the power system presented in [3].

This paper will discuss the stability correlated to the large-scale wind power integration into modern power systems. Firstly, the dynamic stability will be studied followed by transient stability study. WTGs mainly are divided into two types accordingly the speed of the wind fixed speed wind turbines [4] and variable speed wind turbines as doubly fed induction generators (DFIG) [5] 


\section{2-CASE STUDY WITH MATLAB SIMULINK}

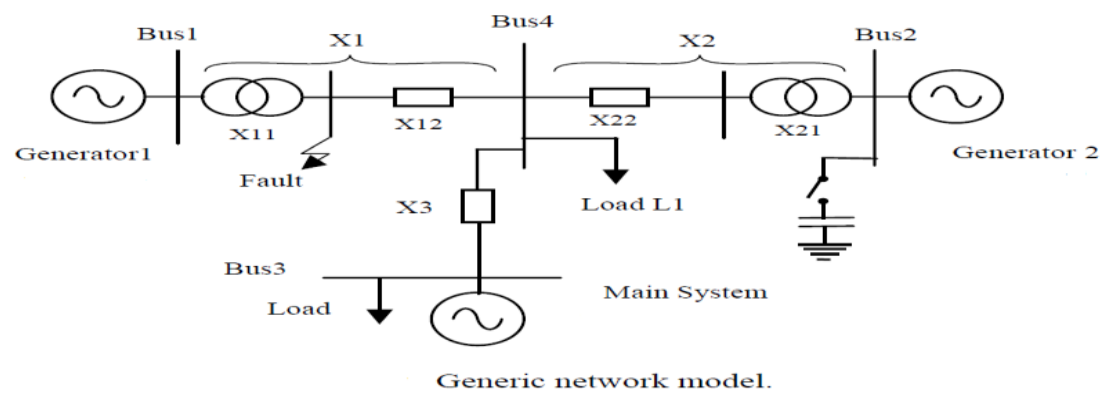

Fig.1 Generic network model

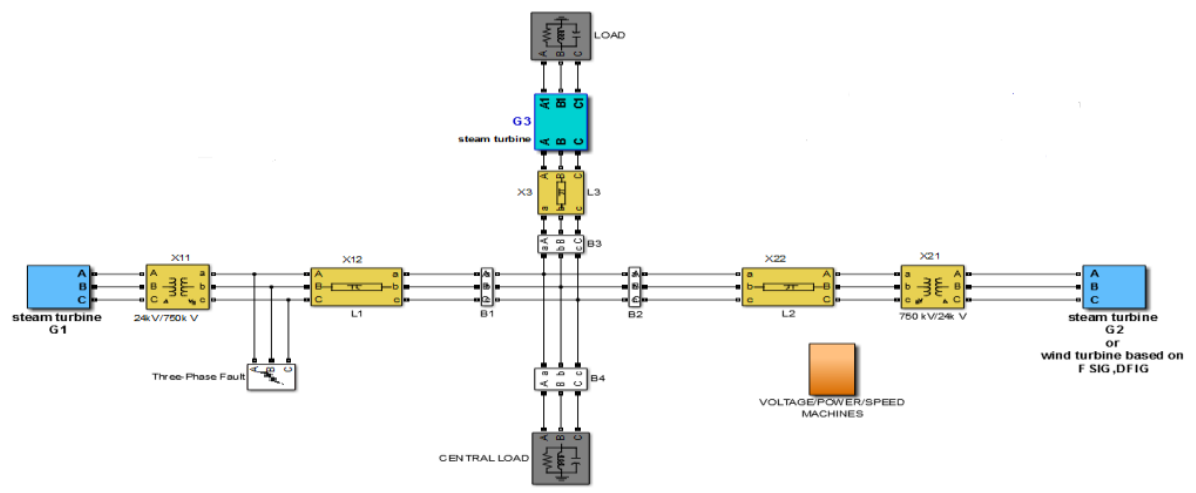

Fig.2 Generic model on Matlab Simulink

The case study is considered in this paper is the generic model of the United Kingdom [6, 7]. It consists of three machines (see Fig.1), the main generator (G3) 21000MVA is CSG, While G1 and G2 have a total overall capacity 5300MVA, (i.e. if the capacity of G2 is increased the capacity of G1 is decreased to keep the total capacity constant at 5300 MVA).

G1 is CSG while G2 will be considered once as CSG another time as FSIG and finally as DFIG. The generic model designed using Matlab Simulink (see Fig.2).all parameters of the generic network in Appendix A

However our case study model will differ a little bit from the model considered in [6] as different excitation [8], automatic voltage regulator (AVR), prime mover with governor [9] and power system stabilizers $[10,11]$ will be considered in our study and all parameters in Appendix A.

Representation of synchronous machines as in [12] and the design of the squirrel cage induction machine is coupled with the wind turbine (FSIG $[14,16]$ or DFIG $[15,16])$ are given in Appendix B.

\section{3- STABILITY STUDY}

- Dynamic stability study by applying Lyapunov's first method $[12,13]$

The stability of nonlinear system is given by the roots $(\lambda)$ of the characteristic equation (A) of the system of first approximations, i.e., by the eigenvalues of $\mathrm{A}$

$\lambda=\sigma_{\mathrm{i}} \pm \mathbf{j w}_{\mathrm{i}} \ldots \ldots \ldots \ldots \ldots$ (1)

When

1- Stable system means $\sigma_{\mathrm{i}}<<0$

2-unstable system means $\sigma_{\mathrm{i}}<>0$ 
$\mathbf{f}-=W_{\text {hen }} \sigma_{\mathrm{i}}=\mathbf{0}$, then nothing can be said in general the frequency of oscillation in, $\mathrm{Hz}$, and 国 $\pi$

- Transient stability study [12]

Is the ability of the power system to maintain synchronism when subjected to a severe transient disturbance [12] such as a fault on transmission facilities loss of generation, or loss of a large load. Stability influenced by nonlinear characteristics of the power system. If a resulting angular separation between the machines in the system remains within certain bounds, the system maintains synchronism. Loss of synchronism is because of transient instability, if it occurs, will usually be evident within 2 to 3 seconds of the initial disturbance.

\section{A-DYNAMIC Stability study}

Eigenvalues were calculated for four conditions on the generation capacity of generator $2(\mathrm{G} 2)$. The situations correspond to values of

i) Generator 2 - 1/10 nominal rating $240 \mathrm{MVA}$; power output approx. $224 \mathrm{MW}$

Generator 1 - 19/10 nominal rating 5320 MVA; power output approx. 4,536 MW

ii) Generator 2 - 1/3 nominal rating $800 \mathrm{MVA}$; power output approx. $750 \mathrm{MW}$

Generator 1 -5/3 nominal rating 4,667 MVA; power output approx. 4,010 MW

iii) Generator 2 - 2/3 nominal rating $1600 \mathrm{MVA}$; power output approx. 1,500 MW

Generator $1-4 / 3$ nominal rating $3733 \mathrm{MVA}$; power output approx. 3,260 MW

iv) Generator 2 - nominal rating 2,400 MVA; power output approx. 2,240 MW

Generator1 - nominal rating $2800 \mathrm{MVA}$; power output approx. 2,520 MW

The eigenvalue analysis was employed to evaluate the way in which both the capacity and type of generator 2 (G2) influence the network damping and dynamic stability characteristics.

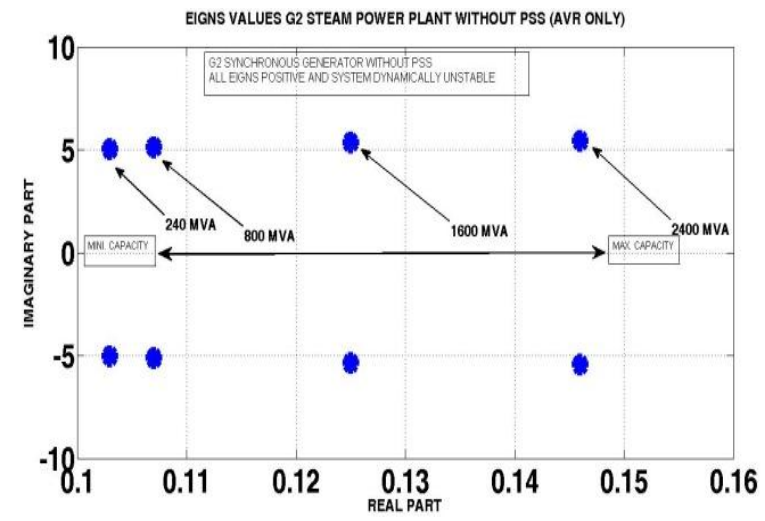

FIG.3.1 Eigen values analysis when all machines are synchronous generators with AVRs only

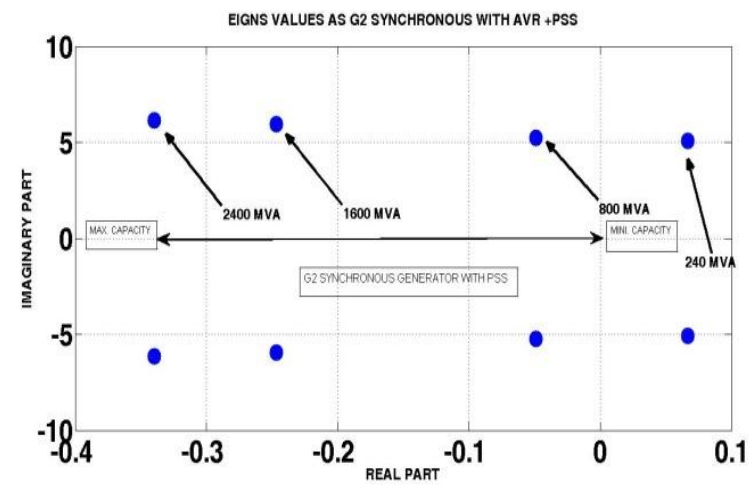

FIG.3.2 Eigen values analysis when all machines are synchronous generators with AVRs + (multi -band) PSS at G2 


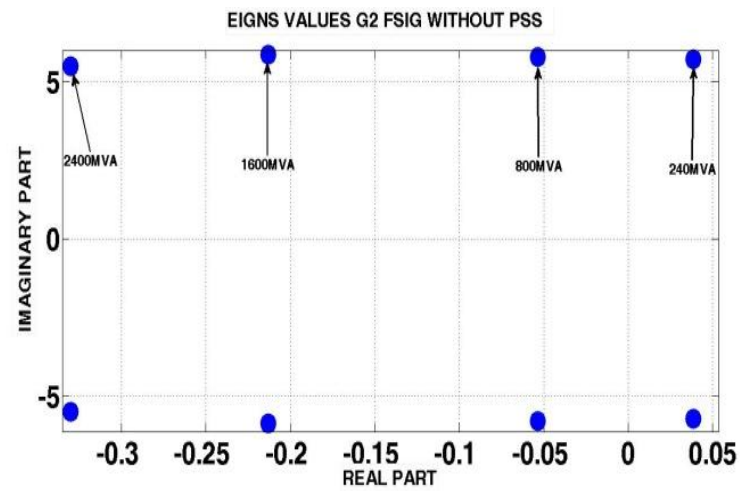

Fig.4.1 Eigenvalues analysis when G2 is FSIG and synchronous machines (G1, G3) with AVRs Only

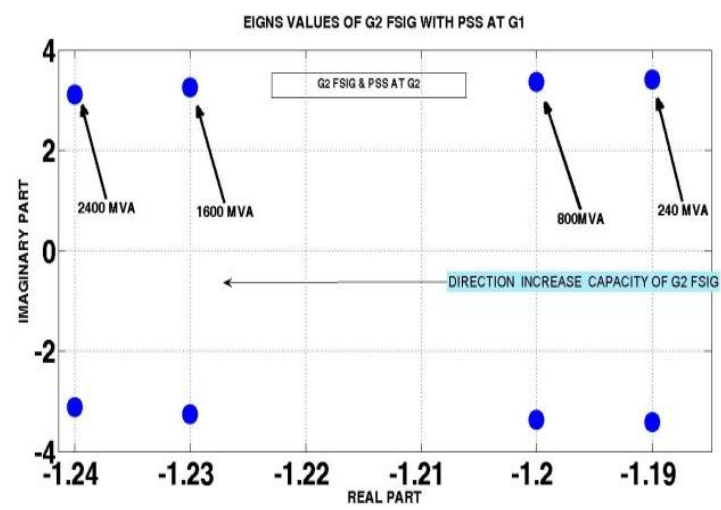

Fig.4.2 Eigen values analysis when G2 is FSIG and synchronous machines (G1, G3) with AVRs \& PSS at G1

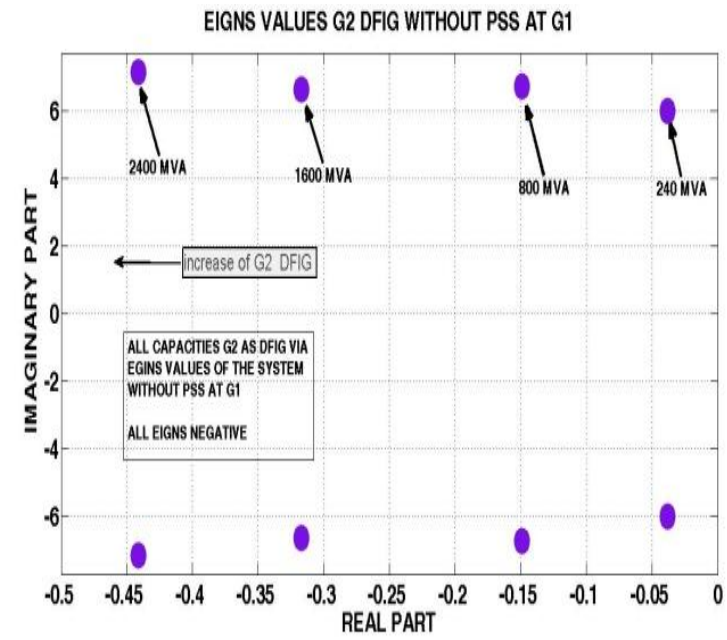

Fig.5 Eigen values analysis when G2 is DFIG and synchronous machines (G1, G3) with AVRs Only 
ASSESMENT OF THE POWER SYSTEM STABILITY WITH LARGE PENETRATION OF WIND TURBINES
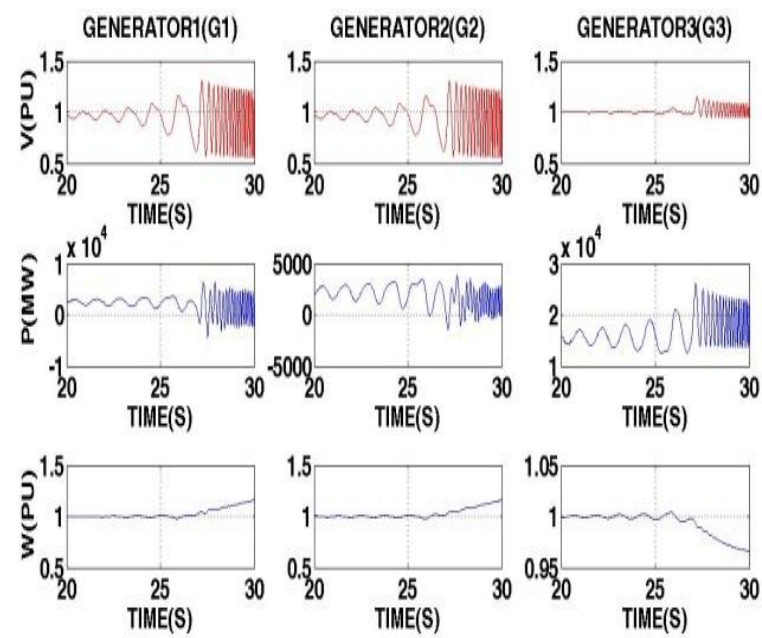

Fig.6.1 Voltages, active powers and speeds of machines when G2 is CSG with AVR Only
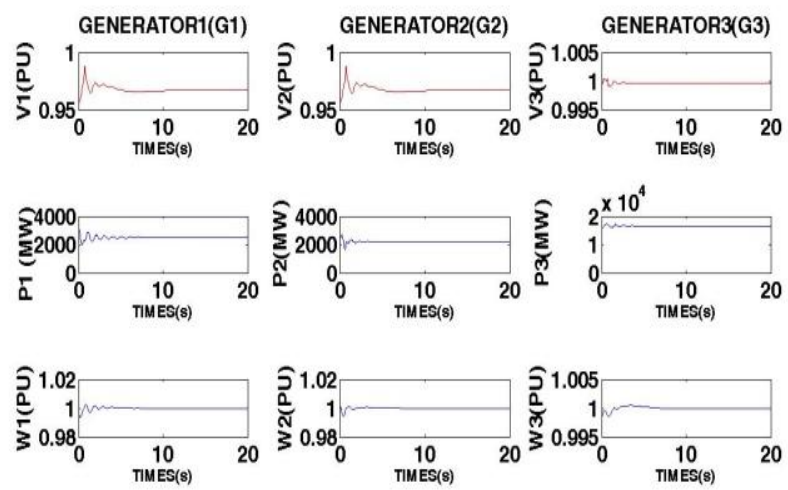

Fig.6.2 Voltages, active powers and speed of machines when G2 is CSG with AVR +PSS (MULTI-BAND)
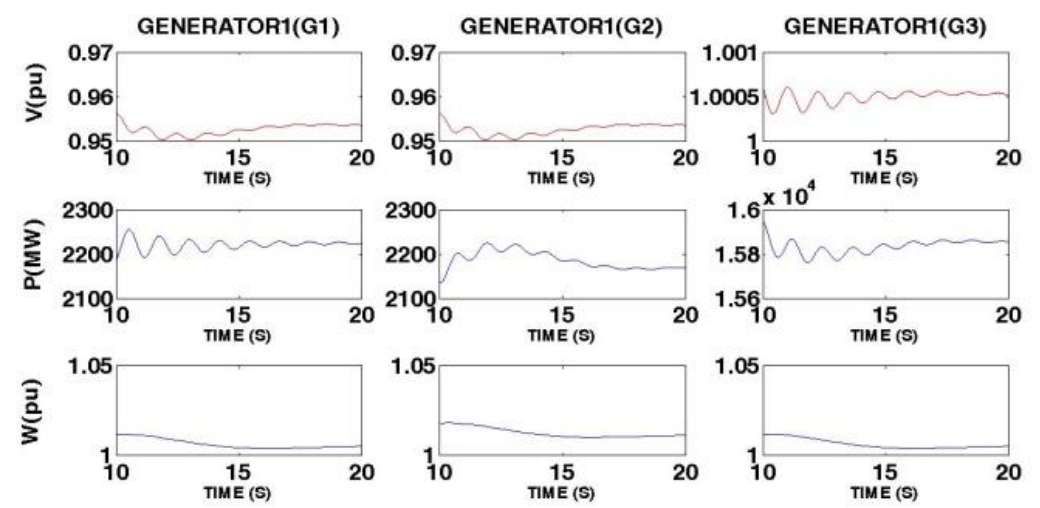

Fig.7 Voltages, active powers and speed of machines when G2 is FSIG and synchronous machines (G1, G3) with AVRs Only 

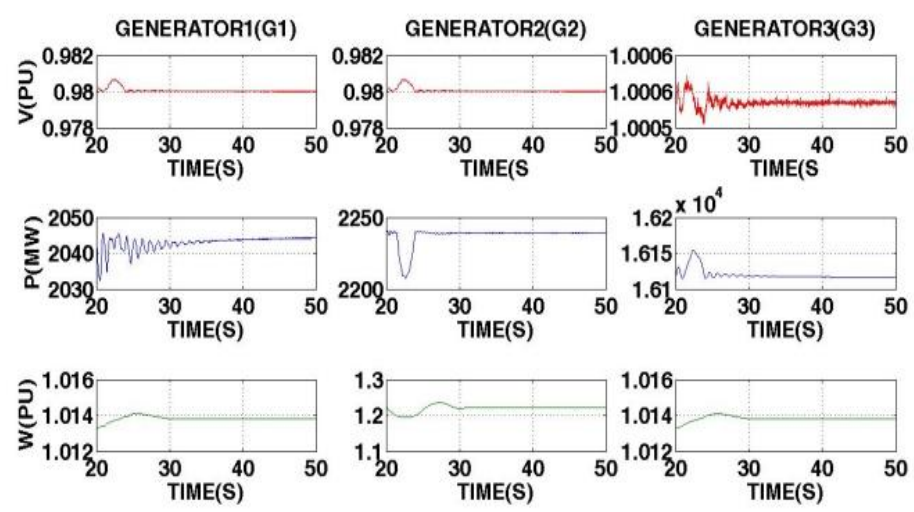

Fig.8 Voltages, active powers and speed of machines when G2 is DFIG and synchronous machines (G1, G3) with AVRs Only

\section{B-TRANSIENT Stability study}

Transient stability study with three phase fault to ground at H.T (high tension) of G1 whiles all generators at nominal generation capacity. The situation corresponds to values of

Generator 2 - nominal rating 2,400 MVA; power output approx. 2,240 MW

Generator 1 - nominal rating $2800 \mathrm{MVA}$; power output approx. 2,520 MW

Generator 3 - nominal rating 21,000 MVA; power output approx. 17,600 MW

Study involves the influence of PSS to the transient stability

PSS is incorporated with G2 in the case of all machines are CSGs.PSS is inserted with G1 in the case of $\mathrm{G} 2$ is taken as WTGs.
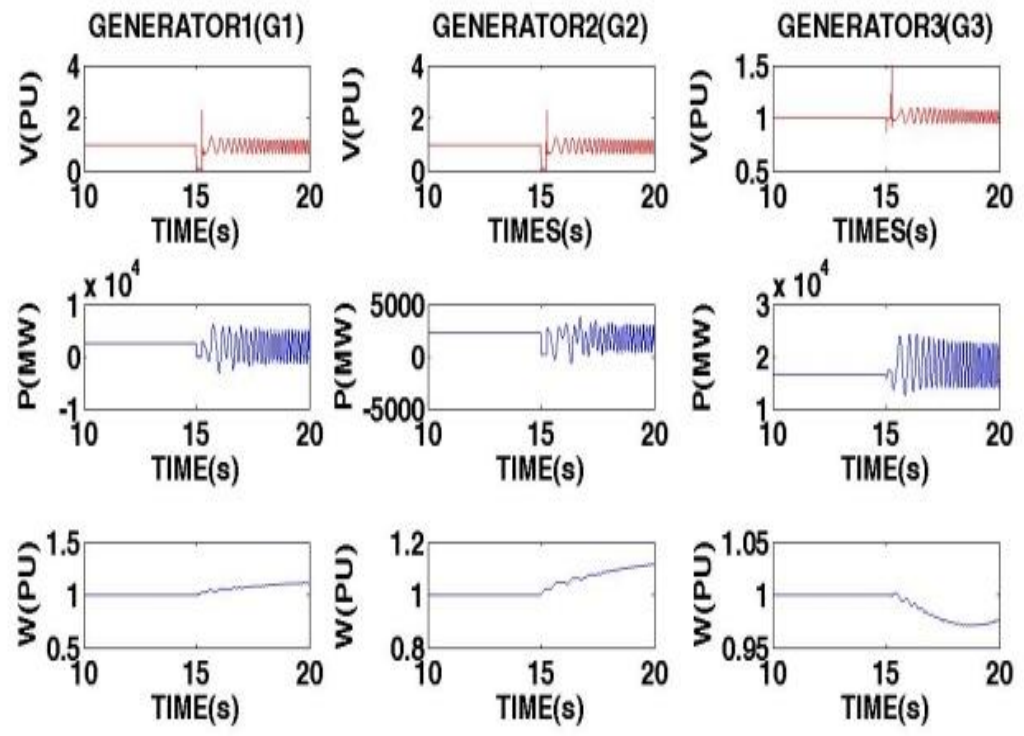

Fig.9 Fault duration $250 \mathrm{~ms} \&$ G2 is a CSG with (multi-band) PSS at G2 

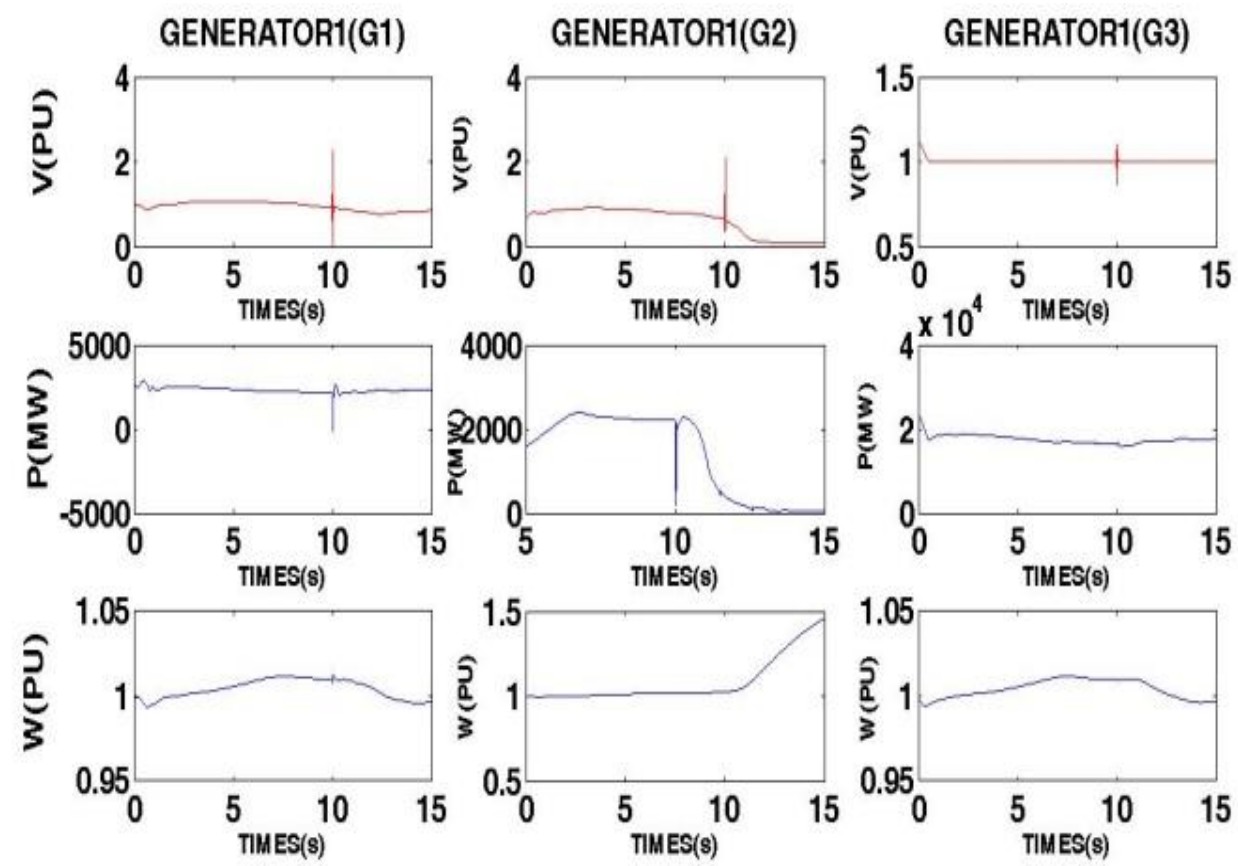

Fig.10.1 Fault duration $30 \mathrm{~ms} \&$ G2 is a FSIG without inserting PSS
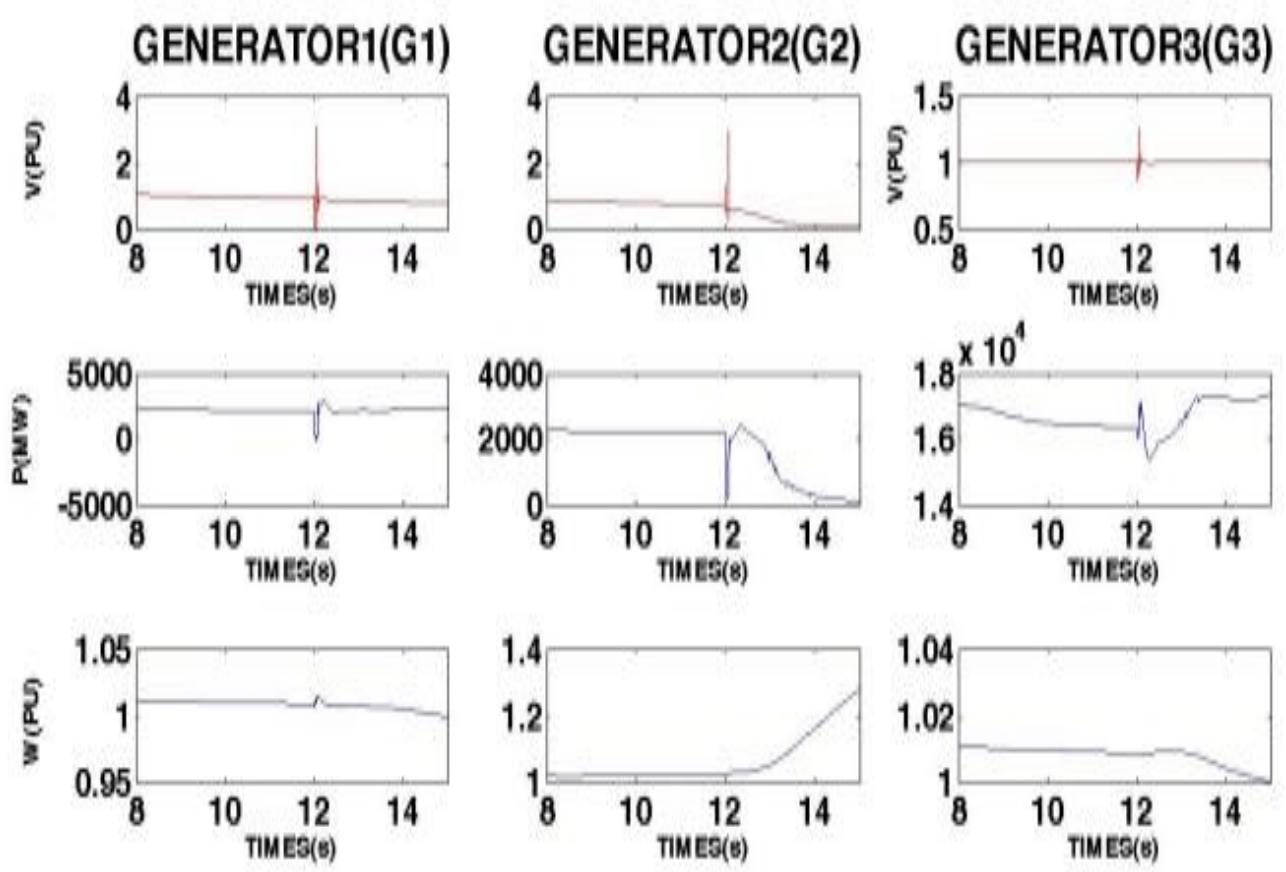

Fig.10.2 Fault duration $60 \mathrm{~ms} \&$ G2 is a FSIG with inserting PSS at G1 

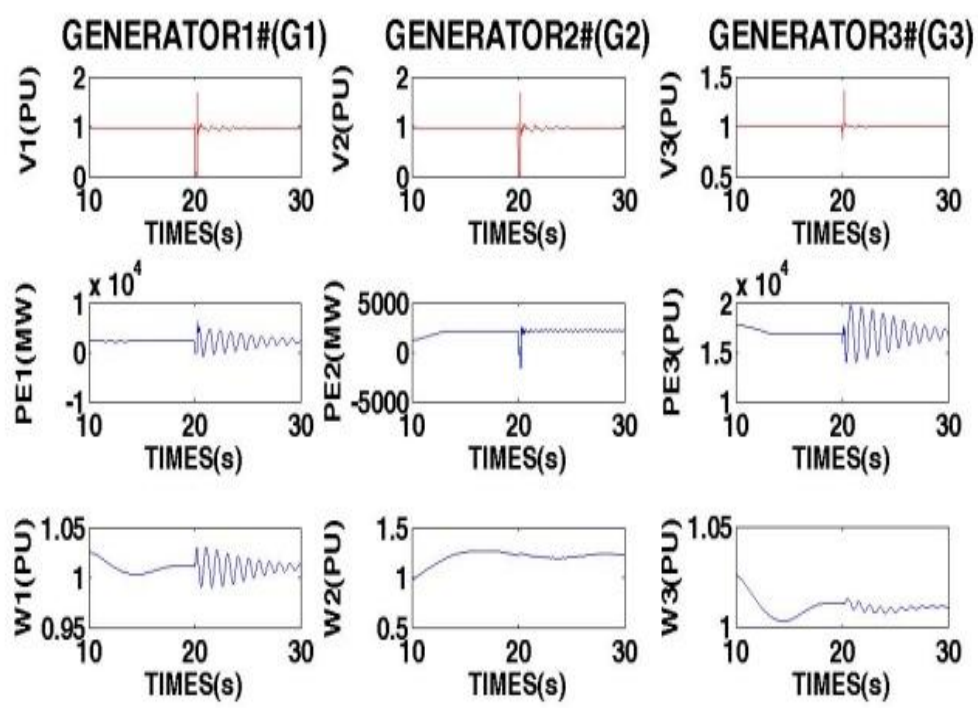

Fig.11.1 Transient performance following Fault duration $200 \mathrm{~ms}$ at H.T of G1 without inserting PSS \& G2 is a DFIG

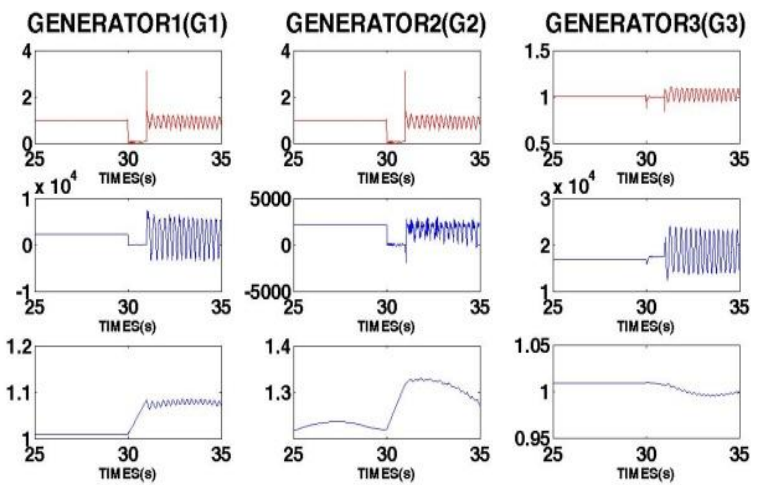

Fig.11.2 Transient performance following Fault duration 270 ms at H.T of G1 without inserting PSS (multiband) \& $\mathbf{G} 2$ is a DFIG
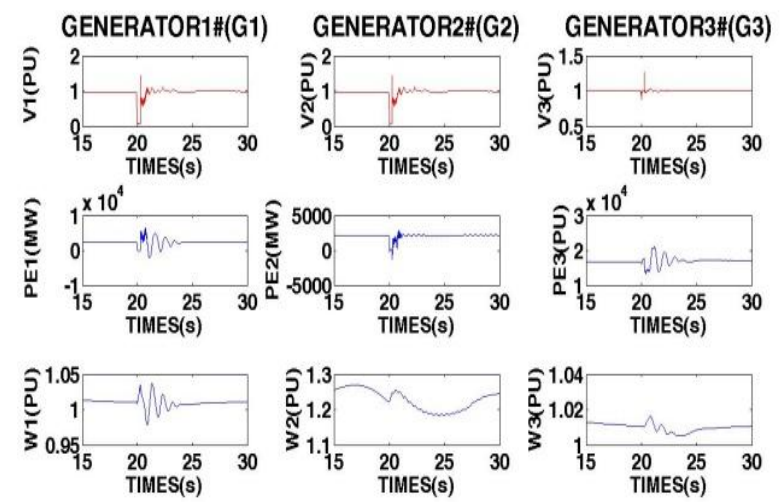

Fig.11.3 Transient performance following Fault duration $270 \mathrm{~ms}$ at H.T of G1 with inserting PSS \& G2 is a DFIG 


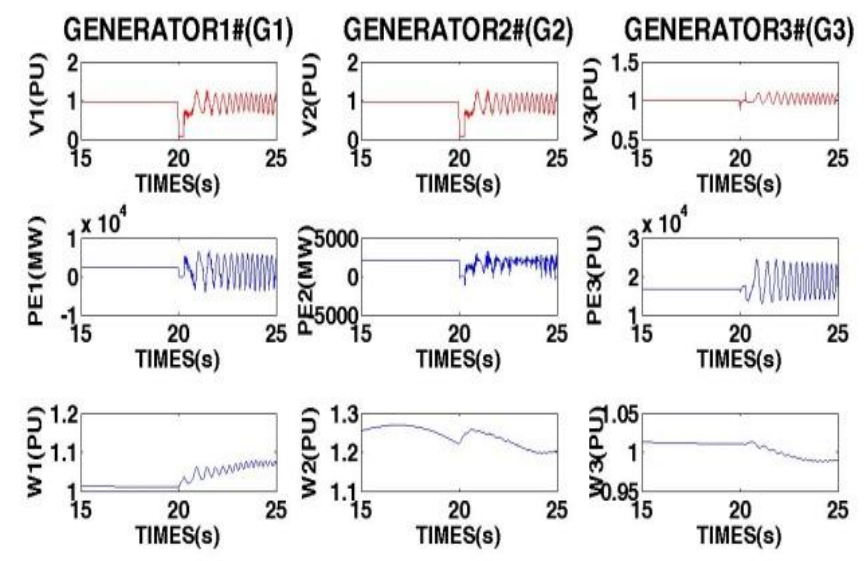

Fig.11.4 Transient performance following Fault duration $290 \mathrm{~ms}$ at H.T of G1 with inserting PSS \& G2 is a DFIG

\section{4-DYNAMIC STABILITY DISCUSSION}

i. $\mathrm{G} 2$ is a $\mathrm{CSG}$

In case G2 is represented as a CSG with AVR only; observed eigenvalues as in fig.3.1 are positive, and the system is dynamically unstable in all capacities of CSG at G2.

All machines' signals of voltages, active powers and speeds are obtained at nominal values of generation and G2 is constructed only with AVR as in fig.6.1, so the system is not stable and eigenvalues located on the right-hand side (positive real part)

G2 is formed with PSS; all eigenvalues are shifted to the left-hand side except the eigenvalue in case 240 MVA as depicted in fig.3.2

All machines' time responses of voltages, active powers and speeds are obtained at nominal values of generation and G2 is constructed with AVR + PSS as in fig.6.2, so the system is stable

ii. $\quad$ G2 is a FSIG

In case G2 is represented as FSIG and synchronous machines G1 and G3 with AVRs only, eigenvalues are perceived as in fig.4.1 are negative except the eigenvalue of G2 240 MVA hence, The system is dynamically stable in all capacities except 240MVA.

Fig.4.2 describes the eigenvalues with inserting PSS at G1 and eigenvalue of capacity is shifted to the left hand side

Fig.7 shows the machines' time response signals of voltages, active powers and speeds at nominal generation hence; the system is dynamically stable without PSS

iii. $\mathrm{G} 2$ is a DFIG

In case, G2 is represented as a DFIG and synchronous machines G1 and G3 with AVRs only, observed eigenvalues as in fig.5 are negative hence; the system is dynamically stable in all capacities of generation. All machines' time responses of signals are taken at nominal values of generation as in fig.8

\section{5-TRANSIENT Stability DISCUSSION}

All machines' time responses of voltages, powers and speeds at rated capacities of machines. As a fig. 9 shows all time responses of voltages, powers, and speeds of machines while G2 is represented as a CSG with PSS (MULTI-BAND SIMPLIFIED MODEL) duration time fault at a high tension of G1 is $250 \mathrm{~ms}$ to obtain instability in the system. 
Fig.10.1 describes the fault duration is $30 \mathrm{~ms}$ needed to trip wind speed generator based on fixed speed wind turbine technology. And with incorporation PSS at G1, the time duration fault increased to $60 \mathrm{~ms}$ as in fig. 10.2

But in the case of a DFIG and without inserting PSS the duration time reached to $200 \mathrm{~ms}$ and the wind turbine will not trip due to flexibility of speed variation as in fig. 11.1 while increasing fault duration till $270 \mathrm{~ms}$ instability conditions are obtained as in fig.11.2.

Fig.11.3 shows that in case of PSS is added with G1 and G2 is a DFIG so the time duration fault is $270 \mathrm{~ms}$ and system returned to its normal condition but fig. 11.4 describes the signals at all machines with fault $290 \mathrm{~ms}$ at high tension of G1 and instability conditions appeared.

\section{6- CONCLUSIONS}

- Eigenvalues analysis is one of the best ways to assess the dynamic stability of the system .it is very sensitive to the whole data and parameters are included with the model.

- The System is dynamically unstable with G2 is implemented as CSG at all stages of capacities without PSS so To stabilize the system we have to insert PSS with G2 while in case of G2 is FSIG we have to use PSS at 240MVA only and we can remove from the system if $\mathrm{G} 2$ is a DFIG.

- Fixed speed induction generator (FSIG) based wind farms can contribute significantly to network damping, but are weak to network faults. Rebates in network voltage due to system collapses can result in a failure of both the terminal voltage and power-producing of the FSIG and be concluding machine 'runaway.'

- DFIG can provide positively to system damping, although to a lesser extent than FSIGs.

- A DFIG based wind farm is able of rendering a good transient performance to that of a conventional synchronous generator following a system fault.

- The results ordinarily intimate that regarding the expansion of renewable energy in mixed generation networks, wind production based entirely on FSIG based wind farms would make the network vulnerable to system faults, would restrict production capacity and pose operational problems.

- The power system stabilizers effect on the dynamic stability of the system, eigenvalues is shifted from positive to negative mode the type of the power system stabilizer is effect also the transient condition

\section{Appendix A}

Table 1: Parameters of network

\begin{tabular}{|c|c|}
\hline $\mathbf{X}_{22}$ & $0.1333 \mathrm{PU}$ \\
\hline $\mathbf{X}_{21}$ & $0.05714 \mathrm{PU}$ \\
\hline $\mathbf{X}_{11}$ & $0.05 \mathrm{PU}$ \\
\hline $\mathbf{X}_{12}$ & $0.01 \mathrm{PU}$ \\
\hline $\mathbf{X}_{\sqrt{\square}}$ & $0.2 \mathrm{PU}$ \\
\hline Base MVA & 1000 \\
\hline
\end{tabular}

Table2: Parameters of synchronous machines (G1, G2 in case of CSG)

\begin{tabular}{|c|c|}
\hline inertia H(s)G1,G2 & 4 \\
\hline $\mathbf{X}_{\square}$ & 1.7668 \\
\hline $\mathbf{X}_{\square}$ & 1.7469 \\
\hline
\end{tabular}




\begin{tabular}{|c|c|}
\hline$x_{d}^{*}\left(x_{q}^{*}\right)$ & $.2738(1.0104)$ \\
\hline $\mathrm{X}_{\mathrm{d}}\left(\mathrm{X}_{\mathrm{q}}^{\alpha *}\right)$ & $.2284(.2239)$ \\
\hline $\mathbf{X}_{\mathrm{\Xi}}$ & .1834 \\
\hline $\mathrm{T}_{\mathrm{d} 0}\left(\mathrm{~T}_{\mathrm{dz}}\right)_{(\mathrm{s})}$ & $5.432(0.042)$ \\
\hline $\mathrm{T}_{\mathrm{q} 0}^{*}\left(\mathrm{~T}_{\mathrm{q}[\mathbb{z}}^{* \pi}\right)_{(\mathrm{s})}$ & $1.5(0.158)$ \\
\hline
\end{tabular}

Table 3: Parameters of synchronous machine (G3)

\begin{tabular}{|c|c|}
\hline inertia $\mathrm{H}(\mathrm{s})$ & 5 \\
\hline $\mathbf{X}_{\mathrm{d}}(\mathbf{a} \mathbf{u})$ & 1.8 \\
\hline $\mathrm{X}_{\mathrm{q}}(\mathbf{a} \mathrm{u})$ & 1.7 \\
\hline $\mathrm{x}_{\mathrm{d}}\left(\mathrm{x}_{\mathrm{q}}^{\prime}\right)(\mathrm{pu})$ & $0.3(0.55)$ \\
\hline $\mathrm{x}_{\mathrm{d}}^{\prime \prime}\left(\mathrm{X}_{\mathrm{q}}^{* \prime}\right)(\mathrm{pu})$ & $0.25(0.25)$ \\
\hline $\mathrm{X}_{\mathrm{l}}(\mathrm{B} \mathrm{u})$ & 0.2 \\
\hline $\mathrm{T}_{\mathrm{d} 0}\left(\mathrm{~T}_{\mathrm{dz}}^{\alpha e}\right)_{(\mathrm{s})}$ & $8(0.03)$ \\
\hline $\mathrm{T}_{\mathrm{q} 0}^{*}\left(\mathrm{~T}_{\mathrm{q} \mid \bar{z}}^{\infty}\right)_{(\mathrm{s})}$ & $0.4(0.05)$ \\
\hline
\end{tabular}

Table 4: Parameters of FSIG or DFIG (G2 in case of WTG)

\begin{tabular}{|c|c|}
\hline stator resistance(pu) & 0.00488 \\
\hline rotor resi[ance(pu) & 0.00549 \\
\hline stator induc]ance (pu) & $2.451 \mathrm{e}-4$ \\
\hline rotor inductance (pu) & $2.641 \mathrm{e}-4$ \\
\hline magnitizing inductance (pu) & 4 \\
\hline ine国tia & 4 \\
\hline \multicolumn{2}{|l}{}
\end{tabular}

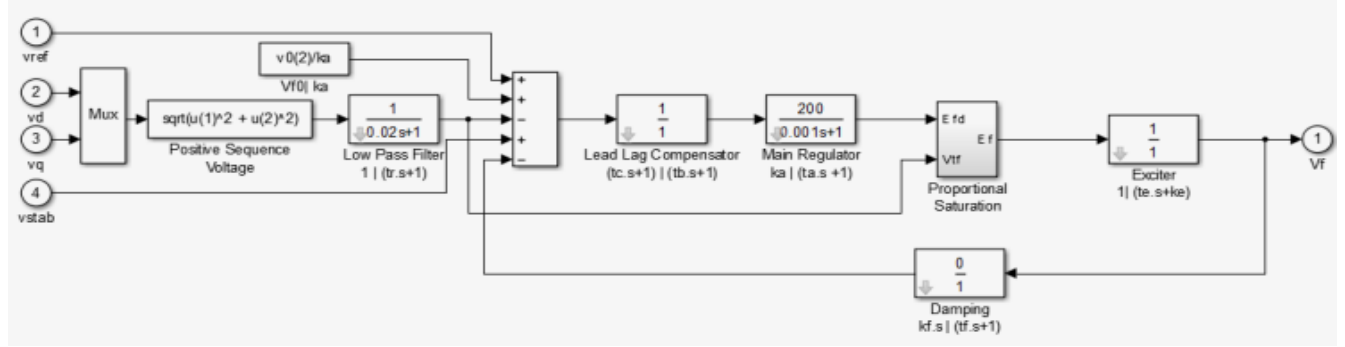

Fig.12 Excitation control model at Matlab Simulink

Table 5: EXCITATION PARAMETERS

\begin{tabular}{|c|c|}
\hline $\mathbf{T}_{\square}(\mathrm{s})$ & $20 \mathrm{e}-3$ \\
\hline $\mathbf{k}_{\square}$ & 200 \\
\hline $\mathbf{T}_{\square}(\mathrm{s})$ & 0.001 \\
\hline $\mathbf{k}_{\square}$ & 1 \\
\hline $\mathbf{T}_{\square}(\mathrm{s})$ & 0 \\
\hline $\mathbf{T}_{\square}(\mathrm{s})$ & 0 \\
\hline
\end{tabular}


ASSESMENT OF THE POWER SYSTEM STABILITY WITH LARGE PENETRATION OF WIND TURBINES

\begin{tabular}{|c|c|}
\hline $\mathrm{T}_{\mathrm{c}}(\mathrm{s})$ & 0 \\
\hline $\mathbf{k}_{\text {[I }}$ & 0 \\
\hline $\mathbf{T}_{\square}(\mathrm{s})$ & 0 \\
\hline $\mathrm{EF}_{\text {MIN }}(\mathrm{pu})$ & 0 \\
\hline $\mathrm{EF}_{\text {MAX }}$ (pu) & 12.3 \\
\hline $\mathbf{K}_{\text {[ }}$ & 0 \\
\hline$V_{t 0}(p u)$ & 1 \\
\hline$V_{\text {fo }}(p u)$ & 2.5837 \\
\hline $\mathrm{T}_{\text {E }}(\mathrm{s})$ & $20 \mathrm{e}-3$ \\
\hline $\mathbf{k}_{\text {[च] }}$ & 200 \\
\hline $\mathbf{T}_{\square}(\mathrm{s})$ & 0.001 \\
\hline $\mathbf{k}_{\mathrm{I}}$ & 1 \\
\hline $\mathrm{T}_{\square}(\mathrm{s})$ & 0 \\
\hline $\mathbf{T}_{\text {[I }}(\mathrm{s})$ & 0 \\
\hline$T_{c}(s)$ & 0 \\
\hline $\mathbf{k}_{\square}$ & 0 \\
\hline $\mathbf{T}_{\square}(\mathrm{s})$ & 0 \\
\hline $\mathrm{EF}_{\text {MIN }}(\mathbf{p u})$ & 0 \\
\hline $\mathrm{EF}_{\text {MAX }}$ (pu) & 12.3 \\
\hline $\mathbf{K}_{\square}$ & 0 \\
\hline$V_{t 0}(p u)$ & 1 \\
\hline$V_{\text {fo }}(p u)$ & 2.5837 \\
\hline $\mathbf{T}_{\square}(\mathrm{s})$ & $20 \mathrm{e}-3$ \\
\hline $\mathbf{k}_{\text {[ }}$ & 200 \\
\hline
\end{tabular}

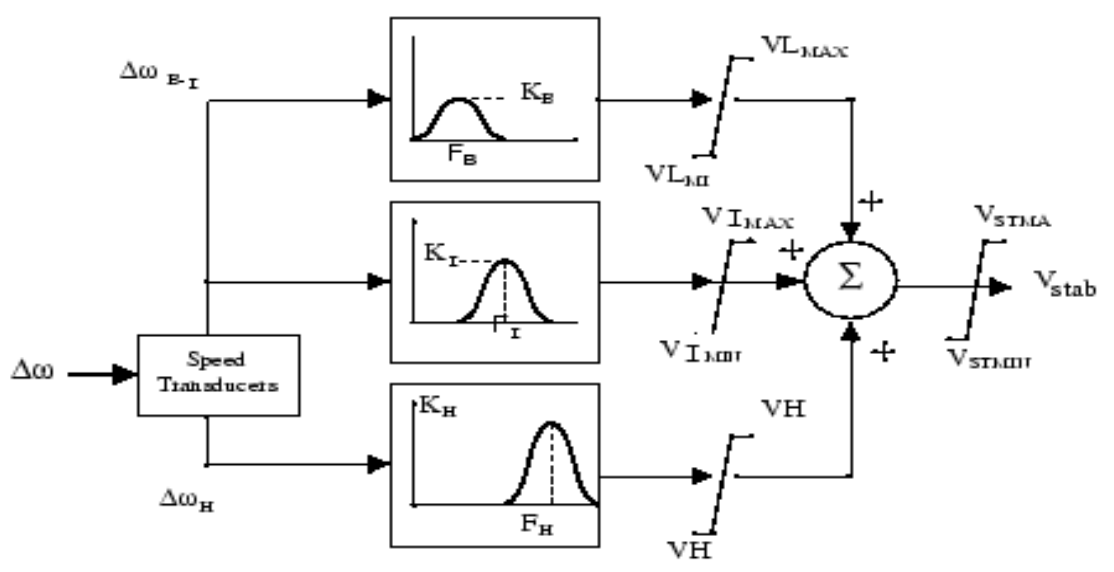

Fig.13 Conceptual Representation of multi band PSS 
Table 6: Power system stabilizer multi band type (MB-PSS) Simplified model

\begin{tabular}{|c|c|}
\hline $\mathbf{F}_{\boldsymbol{L}}(\mathrm{HZ})$ & 0.2 \\
\hline $\boldsymbol{k}_{\mathrm{L}}$ & 30 \\
\hline $\mathbf{F}_{\boldsymbol{I}}(\mathrm{HZ})$ & 1.25 \\
\hline $\boldsymbol{k}_{\mathrm{I}}$ & 40 \\
\hline $\mathbf{F}_{\boldsymbol{H}}(\mathrm{HZ})$ & 12 \\
\hline $\boldsymbol{k}_{\mathrm{H}}$ & 160 \\
\hline $\mathbf{V}_{\text {LMAX }}$ & 0.075 \\
\hline $\mathbf{V}_{\text {IMAX }}$ & 0.15 \\
\hline $\mathbf{V}_{\text {HMAX }}$ & 0.15 \\
\hline $\mathbf{V}_{\text {SMAX }}$ & 0.15 \\
\hline
\end{tabular}

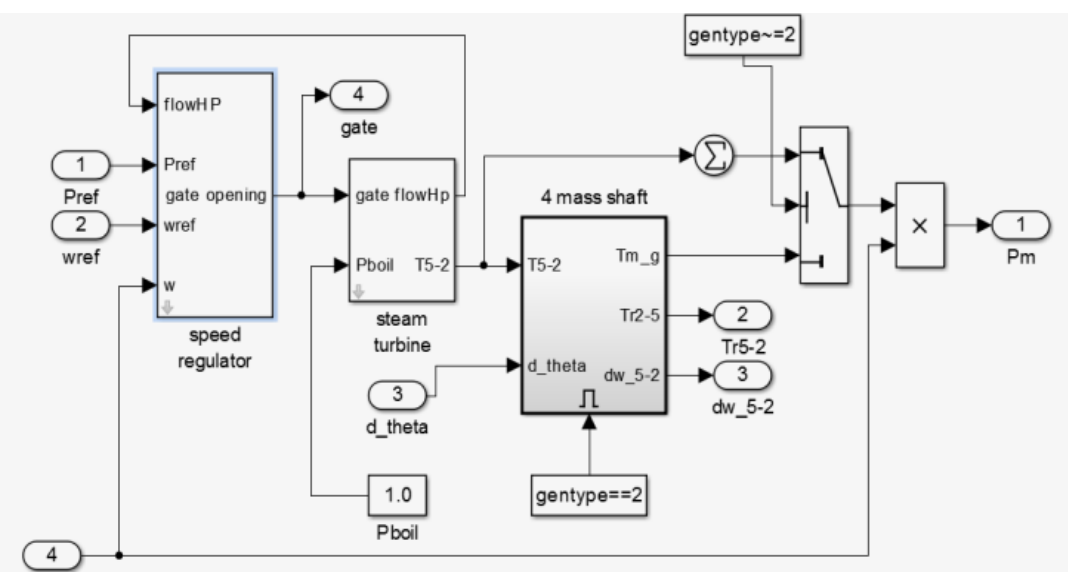

Fig.14.1 Speed regulator + prime mover single mass generator with steam turbine with Matlab Simulink

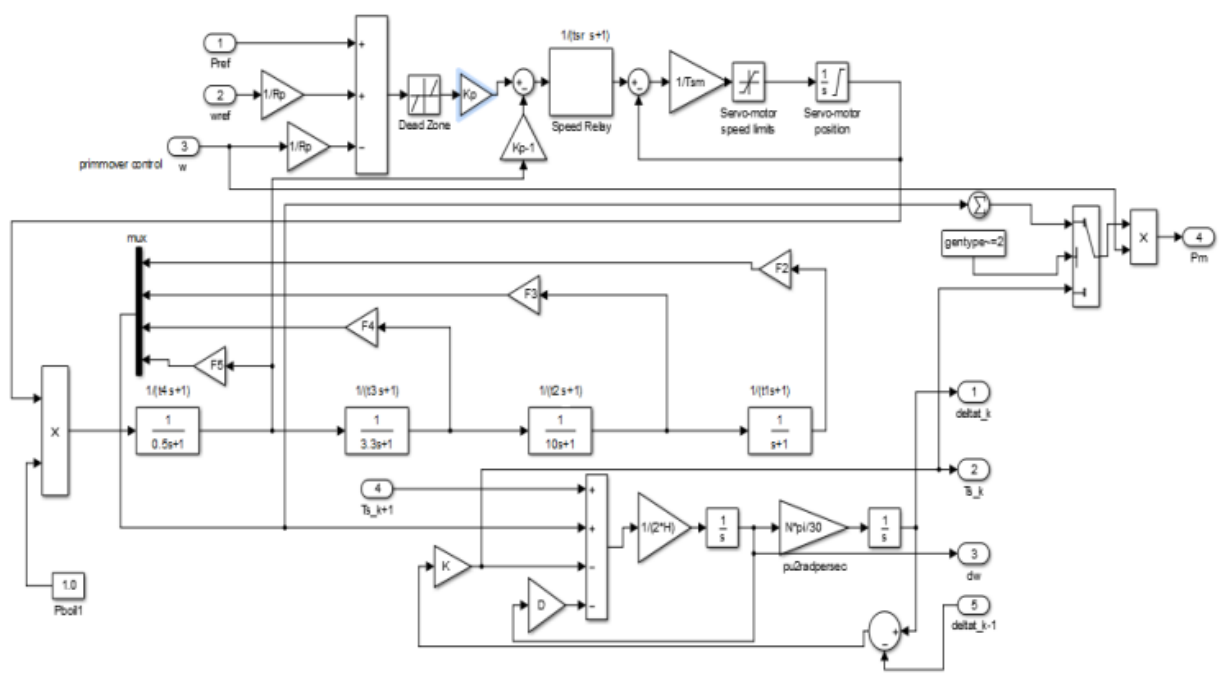

Fig.14.2 Prime mover and speed regulator and steam turbine representation in details as one mass generator Table 7: Parameters of speed regulator \&steam turbine and prime mover 


\section{Appendix B}

\begin{tabular}{|c|c|}
\hline 1 & $\mathbf{K}_{\mathrm{g}}$ \\
\hline 0.05 & $\mathbf{R}_{\text {घ }}(\mathrm{pu})$ \\
\hline 0 & $\mathbf{D}_{\Xi}(\mathrm{pu})$ \\
\hline .001 & $\mathbf{T}_{\mathrm{s} \mathbb{I}(\mathrm{s})}$ \\
\hline 0.15 & $\mathbf{T}_{\mathrm{s} \mathbb{}(\mathrm{s})}$ \\
\hline-0.1 & $\mathbf{V}_{\mathrm{g} m \Sigma \mathbf{n}}(\mathrm{pu} / \mathrm{s})$ \\
\hline 0.1 & $V_{\max }(\mathrm{pu} / \mathrm{s})$ \\
\hline 0 & $\mathbf{g m} \mathbf{I}^{\mathbf{n}}(\mathrm{pu})$ \\
\hline 4.496 & $\mathbf{g m} \mathbf{Z l}_{\mathbf{x}}(\mathrm{pu})$ \\
\hline 3600 & $\mathbf{w}_{\Xi}$ (r.p.m) \\
\hline 0 & $\mathrm{~T}_{\text {घ }}(\mathrm{s})$ \\
\hline 10 & $\mathrm{~T}_{\square}(\mathrm{s})$ \\
\hline 3.3 & $\mathrm{~T}_{\square}(\mathrm{s})$ \\
\hline 0.5 & $\mathrm{~T}_{\text {ए }}(\mathrm{s})$ \\
\hline 0 & $F_{E}$ \\
\hline 0.36 & $\mathrm{~F}_{\mathrm{E}}$ \\
\hline 0.36 & $\mathbf{F}_{[\sqrt{2}}$ \\
\hline 0.28 & $F_{\square}$ \\
\hline glit mass & generator type \\
\hline
\end{tabular}

- Synchronous machine representation with $\mathbf{6}^{\mathrm{t} \text {. }}$ order state model as in fig.15 and equations as in table 8 describes the synchronous machine representation in d-q frame.
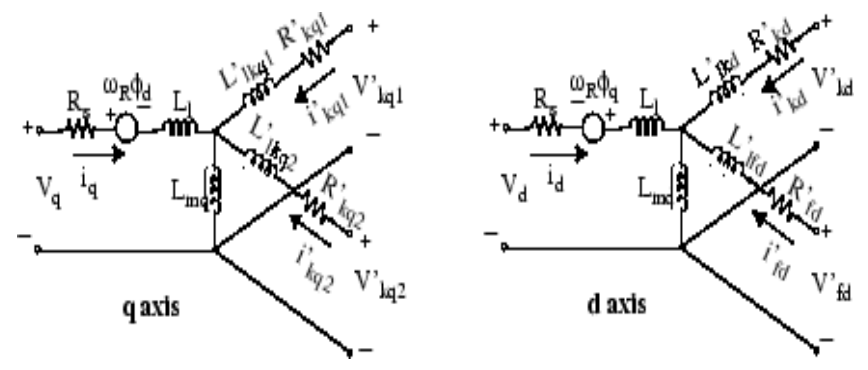

Fig.15 Synchronous machine representation in d-q frame

- The following abbreviations are used:

- $\quad$ d,q: d and q axis quantity

- $\quad$ R,s: Rotor and stator quantity

- $\quad 1, \mathrm{~m}$ : Leakage and magnetizing inductance

- $\quad$ f,k: Field and damper winding quantity

Tabl e 8: synchronous machine representation 
ASSESMENT OF THE POWER SYSTEM STABILITY WITH LARGE PENETRATION OF WIND TURBINES

\begin{tabular}{|c|c|}
\hline $\begin{aligned} V_{\mathrm{d}}= & \mathbf{R}_{\mathrm{s}} \mathbf{I}_{\mathrm{d}}+\frac{\mathrm{d} \varphi_{\mathrm{d}}}{\text { 目 } t} \\
& +{ }^{\omega_{\mathrm{R}} \varphi_{\mathrm{q}}}\end{aligned}$ & 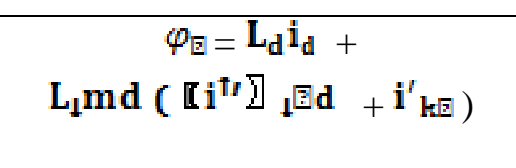 \\
\hline $\begin{aligned} \mathbf{V}_{\mathbf{q}}= & \mathbf{R}_{\mathrm{s}} \mathbf{I}_{\mathrm{q}}+\frac{\mathrm{d} \varphi_{\mathrm{q}}}{[\mathrm{a} \mathbf{t}} \\
& +\omega_{\mathrm{K}} \varphi_{\mathrm{d}}\end{aligned}$ & $\varphi_{\bar{\nabla}}=\mathbf{L}_{\mathbf{q}} \mathbf{i}_{\mathrm{q}}+\mathbf{L}_{\mathrm{mq}} \mathbf{i}_{\mathrm{kq}}^{\prime}$ \\
\hline $\begin{array}{c}\mathbf{V}_{\mathrm{fd}}^{\prime}=\mathbf{R}_{\mathrm{fd}}^{\prime} \mathbf{i}_{\mathrm{fd}}^{\prime}+ \\
\frac{\mathrm{d} \varphi_{\mathrm{fd}}^{\prime}}{\mathrm{G} \mathbf{t}}\end{array}$ & 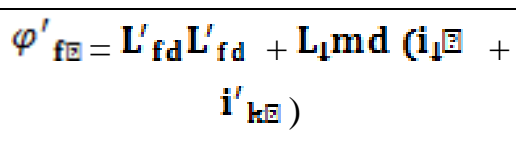 \\
\hline 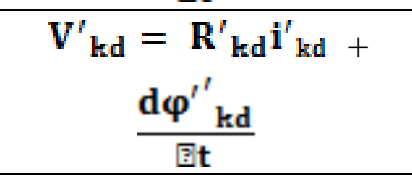 & 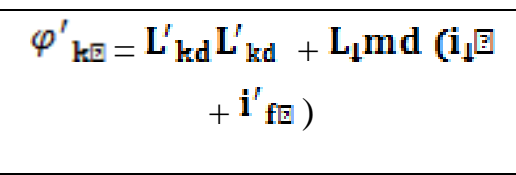 \\
\hline $\begin{array}{c}\mathbf{V}_{\mathrm{kq} 1}^{\prime}=\mathbf{R}_{\mathrm{kq} 1}^{\prime} \mathbf{I}_{\mathrm{kq} 1}^{\prime}+ \\
\frac{\mathrm{d} \varphi_{\mathrm{kq} 1}^{\prime}}{\mathrm{dt}}\end{array}$ & $\varphi_{\mathrm{k} \nabla 1}^{\prime}=\mathbf{L}_{\mathrm{kq} 1}^{\prime} \mathbf{L}_{\mathrm{kq} 1}^{\prime}+\mathbf{L}_{\mathrm{mq}} \mathbb{1}_{\mathrm{q}}$ \\
\hline $\begin{array}{c}\mathbf{V}_{\mathbf{k q} 2}^{\prime}=\mathbf{R}_{\mathbf{k q 2}}^{\prime} \mathbb{I}_{\mathbf{k q} 2}^{\prime}+ \\
\frac{\mathrm{d} \varphi_{\mathbf{k q} 2}^{\prime}}{\mathrm{dt}}\end{array}$ & 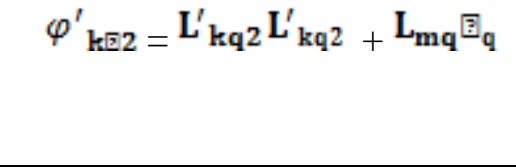 \\
\hline
\end{tabular}

- Squirrel cage induction machine with FSIG and DFIG wind turbine representation in d-q frame with $4^{\text {ti }}$ order state model as in fig.16 and equations as in table 9 describes the squirrel cage induction machine in $\mathrm{d}-\mathrm{q}$ frame.

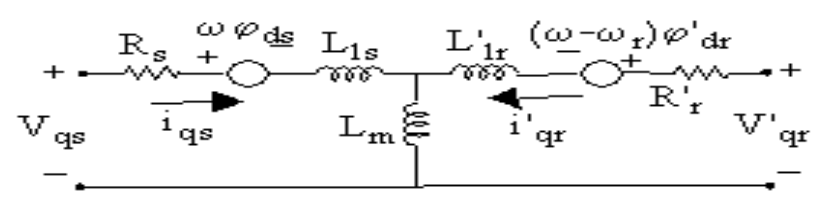

(a) q-axis

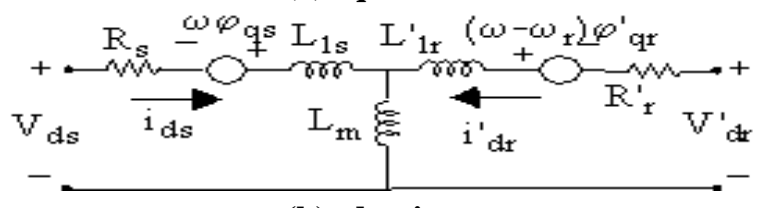

(b) d-axis

Fig.16: Electrical system of the squirrel cage

(a) q-axis and (b) d-axis. 
Table 9: squirrel cage induction machine equations

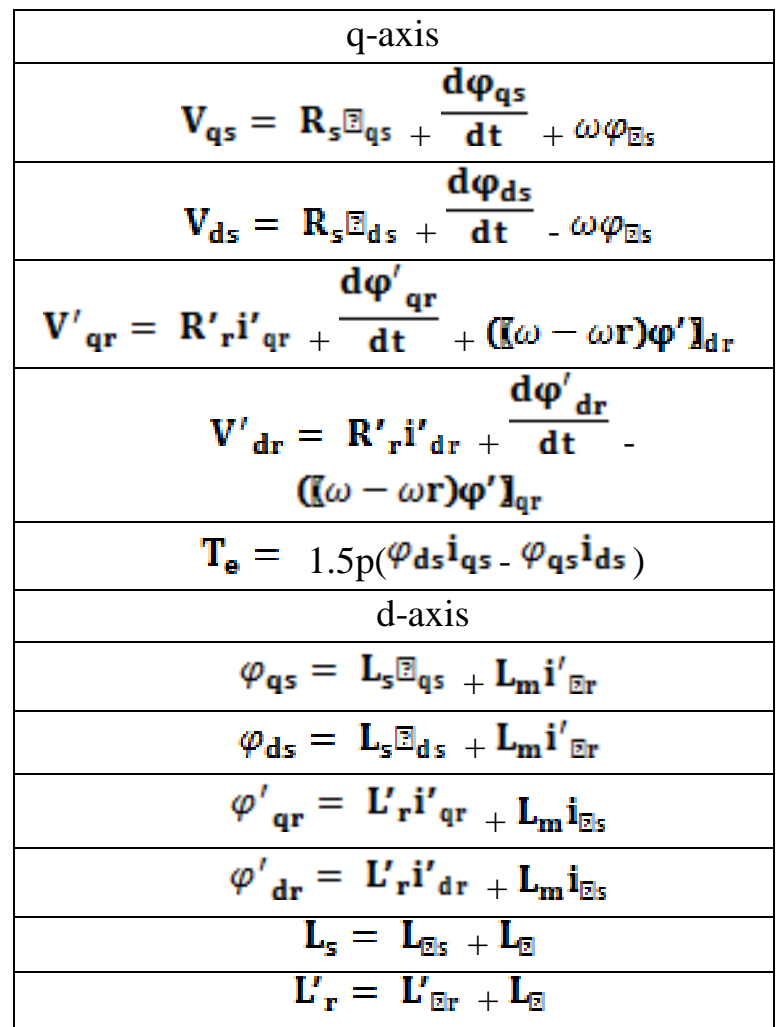

Note: in case of fixed speed wind turbine modeling $V^{\prime}{ }_{\mathbf{r}}=\mathbf{0}$

\section{REFERENCES}

[1] L. Holdsworth, G Wu, J.B Ekanayake and N. Jenkins , "Comparison of fixed speed and doubly-fed induction wind turbines during power system disturbances" , IEE Proceedings: Generation, Transmission, Distribution , vol. 150 , no. 3 , pp.343 -352

[2] V.Akhmatov,"Analysis of Dynamic Behaviour of Electric Power Systems with Large Amount of Wind Power". PhD Thesis, Technical University of Denmark, April 2003, pp. 261. [3] Ayodele TR, Jimoh AA, Munda JL, Agee JT. "The influence of wind power on the small signal stability of a power system", In: International conference on renewable energies and power quality; 2011.

[4]D. Thakur and N. Mithulananthan, "Influence of Constant Speed Wind Turbine Generator on Power System Oscillation," Electric Power Components and Systems, vol. 37, pp. 478 - 494, 2009.

[5] ANJU. M, R. RAJASEKARAN " Performance Analysis of DFIG Based Wind Power Generation under Unbalanced Conditions", International Electrical Engineering Journal (IEEJ), Vol. 4 (2013) No. 1, pp. 899-906, ISSN 2078-2365

[6] O. Anaya-Lara , "Influence of wind farms on power system dynamic and transient stability" , WindEng. , vol. 30 , no. 2 , pp.107 -127, 2006

[7]ANAYA-LARA, O. HUGHES, M. and JENKINS, N., "Generic network model for wind farm control scheme design and performance assessment" ,Proceedings of the EWEC 2005 (European Wind Energy Conference), London, UK, 2005.

[8]"Recommended Practice for Excitation System Models for Power System Stability

Studies,"IEEE Standard 421.5-1992, August, 1992.

[9] IEEE Subsynchronous resonance workinggroup, "Second benchmark model for computer simulation of subsynchronousresonance," IEEE Transactions on Power Apparatusand Systems, Vol.PAS-104, No.5,1985, pp.1057-1066. 
[10] "IEEE Recommended Practice for Excitation System Models for Power System Stability Studies", IEEE St. 421.5-2002.

[11]Mobarak Youssef, Naoto Yorino and Yoshifumi Zoka,“ A Simulink Multi-Band Power System Stabilizer (MB-PSS) and Static Var Compensator (SVC) Controls", Proc. of the Institute of Electrical Engineers of Japan, IEEJ'07, Nagoya, Japan, pp. 25-30, on July 31th -Agu. 2nd (2007).

[12] P. Kundur. Power system stability and control. EPRI, McGraw-Hill, New Jork, 1994, pp. 1176.

[13] D. Y. Wong, "Eigenvalue analysis of very large power systems" , IEEE Trans. PowerSyst. , vol. 3 , pp.472 -480, 1988

[14] Krause, P.C., O. Wasynczuk, and S.D. Sudhoff, Analysisof Electric Machinery, IEEE Press, 2002.

[15] R. Pena, J.C. Clare, G.M. Asher, "Doubly fed induction generator using back-to-back PWM converters and its application to variable-speed wind-energy generation," IEEE Proc.-Electr.

Power Appl., Vol. 143, No. 3, May 1996

[16] Siegfried Heier, "Grid Integrationof Wind Energy Conversion Systems," John Wiley \& Sons Ltd,1998, ISBN 0-471-97143-X 